\title{
Layered Iron Vanadate as a High-Capacity Cathode Material for Nonaqueous Calcium-Ion Batteries
}

\author{
Munseok S. Chae ${ }^{1}\left(\mathbb{D}\right.$, Dedy Setiawan ${ }^{1}$, Hyojeong J. Kim ${ }^{1}$ and Seung-Tae Hong ${ }^{1,2, *(\mathbb{C})}$ \\ 1 Department of Energy Science and Engineering, DGIST (Daegu Gyeongbuk Institute of Science \\ and Technology), Daegu 42988, Korea; anstjr90@dgist.ac.kr (M.S.C.); dedys_id@dgist.ac.kr (D.S.); \\ nj0315@dgist.ac.kr (H.J.K.) \\ 2 Energy Science and Engineering Research Center, DGIST (Daegu Gyeongbuk Institute of Science \\ and Technology), Daegu 42988, Korea \\ * Correspondence: st.hong@dgist.ac.kr; Tel.: +82-53-785-6415
}

check for updates

Citation: Chae, M.S.; Setiawan, D.; Kim, H.J.; Hong, S.-T. Layered Iron Vanadate as a High-Capacity Cathode Material for Nonaqueous Calcium-Ion Batteries. Batteries 2021,

7,54. https://doi.org/10.3390/ batteries7030054

Academic Editor: Carlos Ziebert

Received: 25 April 2021

Accepted: 22 July 2021

Published: 9 August 2021

Publisher's Note: MDPI stays neutral with regard to jurisdictional claims in published maps and institutional affiliations.

Copyright: (c) 2021 by the authors. Licensee MDPI, Basel, Switzerland. This article is an open access article distributed under the terms and conditions of the Creative Commons Attribution (CC BY) license (https:// creativecommons.org/licenses/by/ $4.0 /)$.

\begin{abstract}
Calcium-ion batteries represent a promising alternative to the current lithium-ion batteries Nevertheless, calcium-ion intercalating materials in nonaqueous electrolytes are scarce, probably due to the difficulties in finding suitable host materials. Considering that research into calcium-ion batteries is in its infancy, discovering and characterizing new host materials would be critical to further development. Here, we demonstrate $\mathrm{FeV}_{3} \mathrm{O}_{9} \cdot 1.2 \mathrm{H}_{2} \mathrm{O}$ as a high-performance calcium-ion battery cathode material that delivers a reversible discharge capacity of $303 \mathrm{mAh} \mathrm{g}^{-1}$ with a good cycling stability and an average discharge voltage of $\sim 2.6 \mathrm{~V}$ (vs. $\mathrm{Ca} / \mathrm{Ca}^{2+}$ ). The material was synthesized via a facile co-precipitation method. Its reversible capacity is the highest among calciumion battery materials, and it is the first example of a material with a capacity much larger than that of conventional lithium-ion battery cathode materials. Bulk intercalation of calcium into the host lattice contributed predominantly to the total capacity at a lower rate, but became comparable to that due to surface adsorption at a higher rate. This stimulating discovery will lead to the development of new strategies for obtaining high energy density calcium-ion batteries.
\end{abstract}

Keywords: calcium-ion battery; cathode material; kazakhstanite; post-lithium-ion battery; layered iron vanadate

\section{Introduction}

Lithium-ion batteries (LIBs) have been an essential energy storage device for mobile applications in the last three decades and have received particular attention for their use in recently commercialized electric vehicles, primarily because of their outstanding energy densities and power [1]. Nevertheless, safety issues, high cost, and the maldistribution of lithium resources are driving researchers toward developing new materials, such as magnesium, calcium, zinc, or aluminum, that can be used as the carrier ion [2]. Among these, calcium-ion batteries (CIBs) have emerged as a highly promising post-LIB technology [3-5], particularly due to the recent innovative developments in their anodes [6-8].

Calcium ions can transfer two electrons per ion, and thus, in principle, the capacity of a host material can double due to the divalency of calcium, provided the host material can release and accept the transferred electrons. The cost of the final battery product is expected to be competitive, owing to the abundant calcium reserves. The redox potential of calcium is slightly higher (by $0.15 \mathrm{~V}$ ) than that of lithium, enabling a high cell voltage. The larger ionic radius of calcium $(1.0 \AA)$ compared to those of other divalent ions $(0.60-0.74 \AA)$ could be a disadvantage because a narrow diffusion pathway sufficient for smaller ions will not allow the passage of larger $\mathrm{Ca}$ ions. However, the larger ionic radius of calcium ions $\left(\mathrm{Ca}^{2+}\right)$ ensures a lower effective intercalant-ion charge density $\left(0.49 \mathrm{e} / \AA^{3}\right)$ than $\mathrm{Zn}^{2+}$ $\left(1.18 \mathrm{e} / \AA^{3}\right), \mathrm{Mg}^{2+}\left(1.28 \mathrm{e} / \AA^{3}\right)$, and $\mathrm{Al}^{3+}\left(4.55 \mathrm{e} / \AA^{3}\right)$, which can be rather advantageous for the diffusion in the host materials and in the electrolytes [9]. 
Despite the latest innovative research progress in anodes and electrolytes, the fabrication of full-cell CIBs is not yet possible, primarily because of their low Coulombic efficiencies and undesirable side reactions. In addition, no promising cathode materials have been developed yet, probably because of a lack of understanding regarding the unique calcium intercalation chemistry, despite the extensive research, including theoretical/computational studies [3]. The calcium-insertion materials in nonaqueous electrolytes reported so far include Prussian-blue analogues [10-14], $\mathrm{CaCo}_{2} \mathrm{O}_{4}$ [15], $\mathrm{NaFePO}_{4} \mathrm{~F}$ [16], $\mathrm{NH}_{4} \mathrm{~V}_{4} \mathrm{O}_{10}$ [17], $\alpha-\mathrm{MoO}_{3}$ [18], $\mathrm{Ca}_{x} \mathrm{MoO}_{3}$ [19], $\mathrm{TiS}_{2}$ [20], $\alpha-\mathrm{V}_{2} \mathrm{O}_{5}$ [21], $\mathrm{CaMnO}_{3}$ [22], $\mathrm{Mg}_{0.25} \mathrm{~V}_{2} \mathrm{O}_{5} \cdot \mathrm{H}_{2} \mathrm{O}$ [23], $\mathrm{VOPO}_{4} \cdot 2 \mathrm{H}_{2} \mathrm{O}$ [24], $\mathrm{NaV}_{2}\left(\mathrm{PO}_{4}\right)_{3}[25,26]$, and $\mathrm{Ca}_{0.13} \mathrm{MoO}_{3} \cdot\left(\mathrm{H}_{2} \mathrm{O}\right)_{0.41}$ [27]. Most of these materials exhibit low Coulombic efficiency, capacity, or cyclability in dried nonaqueous electrolytes. $\mathrm{Mg}_{0.25} \mathrm{~V}_{2} \mathrm{O}_{5} \cdot \mathrm{H}_{2} \mathrm{O}, \mathrm{VOPO}_{4} \cdot 2 \mathrm{H}_{2} \mathrm{O}$, and $\mathrm{Ca}_{0.13} \mathrm{MoO}_{3} \cdot\left(\mathrm{H}_{2} \mathrm{O}\right)_{0.41}$ are known to possess the highest reversible capacities (100-190 $\mathrm{mAh}^{-1}$ ) to date, and hence, appear to be the best intercalation-based host materials. Thus, to obtain successful CIBs, so as to move past the LIBs, development of high-performance cathode materials is crucial.

Herein, we report that layered iron vanadate $\mathrm{FeV}_{3} \mathrm{O}_{9} \cdot 1.2 \mathrm{H}_{2} \mathrm{O}$ is a potential cathode material for nonaqueous CIBs. Calcium ions could be reversibly intercalated into the material with a high Coulombic efficiency at room temperature. The material has the highest capacity (303 $\left.\mathrm{mAh} \mathrm{g}^{-1}\right)$ reported thus far, and has an excellent cyclability at room temperature. It is also the first example where the capacity exceeds those $\left(150-250 \mathrm{mAh} \mathrm{g}^{-1}\right)$ of conventional LIB cathode materials.

Iron vanadates are naturally abundant compounds and include fervanite $\left(\mathrm{Fe}_{4} \mathrm{~V}_{4} \mathrm{O}_{16}\right.$. $\left.5 \mathrm{H}_{2} \mathrm{O}\right)$ [28], navajoite $\left(\mathrm{FeV}_{9} \mathrm{O}_{24} \cdot 12 \mathrm{H}_{2} \mathrm{O}\right)$ [29], kazakhstanite $\left(\mathrm{FeV}_{3} \mathrm{O}_{9} \cdot 2.6 \mathrm{H}_{2} \mathrm{O}\right.$ or $\mathrm{Fe}_{5} \mathrm{~V}_{15} \mathrm{O}_{39}$ $\left.(\mathrm{OH})_{9} \cdot 9 \mathrm{H}_{2} \mathrm{O}\right)$ [30]. Among these, kazakhstanite has a layered structure with a large interlayer spacing $\left(d_{002}=10.6 \AA\right)$. It was first reported in 1989 as a new mineral, and its synthesis was reported later in 2002 [30,31]. Although it has been studied for lithium and zinc ion storage, a detailed material characterization is lacking and the intercalation mechanism is still elusive [32,33]. In this study, we attempted to synthesize kazakhstanite, but obtained a compound with the formula $\mathrm{FeV}_{3} \mathrm{O}_{9} \cdot 1.2 \mathrm{H}_{2} \mathrm{O}$ (FVO) under our synthetic conditions, which is similar to kazakhstanite in structure except for the crystal water content.

\section{Experimental}

\subsection{Synthesis and Materials Characterization}

Layered iron vanadate $\mathrm{FeV}_{3} \mathrm{O}_{9} \cdot 1.2 \mathrm{H}_{2} \mathrm{O}$ was prepared via a facile co-precipitation method [33]. Three millimoles of $\mathrm{NH}_{4} \mathrm{VO}_{3}(99 \%$, Alfa Aesar, Haverhill, MA, USA) was dissolved into $100 \mathrm{~mL}$ of distilled water with stirring for one hour at $90^{\circ} \mathrm{C}$. Then, $10 \mathrm{~mL}$ of $0.1 \mathrm{M} \mathrm{Fe}\left(\mathrm{NO}_{3}\right)_{3} \cdot 9 \mathrm{H}_{2} \mathrm{O}(98 \%$, Sigma-Aldrich, St. Louis, MO, USA) solution was slowly added to the $\mathrm{NH}_{4} \mathrm{VO}_{3}$ solution and kept for one day at $90{ }^{\circ} \mathrm{C}$. The initial solution was transparent yellow, and the insoluble colloidal products were opaque brown. The brown precipitates were collected by filtration with aspiration and carefully washed with distilled water three times before being dried at $80^{\circ} \mathrm{C}$ in air overnight. The analyses of morphology and elemental composition were performed using field-emission scanning electron microscopy (FE-SEM, Hitachi SU-8020), field-emission transmission electron microscopy (FE-TEM, Hitachi HF-3300) with an energy dispersive X-ray spectroscopy (EDX) attachment, and inductively coupled plasma optical emission spectroscopy (ICP-OES, Varian 700-ES). The amount of crystal water in the samples was determined by thermogravimetric (TG) analysis (Rigaku TG 8120). The trace amount of water in the electrolyte was analyzed by the Karl Fischer titrator (831 KF coulometer, Metrohm, Herisau, Switzerland).

\subsection{Electrochemical Characterization}

Customized homemade cells were used for the electrochemical measurements (Figure S1). The cathode (working electrode) was composed of $\mathrm{FeV}_{3} \mathrm{O}_{9} \cdot 1.2 \mathrm{H}_{2} \mathrm{O}$, conducting carbon (Super P, Timcal Graphite \& Carbon), and poly(vinylidene fluoride) binder (W\#1300, Kureha Co.) in an 8:1:1 weight ratio. A slurry was prepared by dispersing the mixture in $\mathrm{N}$-methyl2-pyrrolidone (NMP) using a planetary centrifugal mixer, and coated on $20 \mu \mathrm{m}$ stainless 
steel foil (SUS-316L, Wellcos Co., Korea). The NMP solvent was removed by drying the coated electrode at $60{ }^{\circ} \mathrm{C}$ in a vacuum oven overnight before the electrode was pressed by an electrode rolling press (Wellcos Co., Seoul, Korea). The loading of $\mathrm{FeV}_{3} \mathrm{O}_{9} \cdot 1 \cdot 2\left(\mathrm{H}_{2} \mathrm{O}\right)$ was $\sim 2.3 \mathrm{mg}$ on each electrode with an area of $1.53 \mathrm{~cm}^{2}$. As the counter and reference electrodes, the activated carbon pellet $(\sim 0.8 \mathrm{~g})$ was used. As the organic electrolyte, $0.5 \mathrm{M}$ calcium perchlorate (Reagent grade, Alfa Aesar) in acetonitrile $(99.8 \%$, Samchun Chemicals, Pyeongtaek, Korea) was used. The calcium perchlorate was dried at $220^{\circ} \mathrm{C}$ for 3 days [34]. Molecular sieves were used to remove water in the electrolyte before use. The water content in the electrolytes was $27 \mathrm{ppm}$ according to water analysis, while it was $38 \mathrm{ppm}$ after the first cycle. As a separator, glass fiber (GF/A, Whatman) was used.

$\mathrm{AC}$ is stable in nonaqueous electrolytes, enabling us to use it as a reference electrode $[35,36]$. The relatively high loading of AC ( 0.8 g) compared to the cathode loading $(\sim 2.3 \mathrm{mg})$ led the AC potential to be almost constant during the cycles. On discharge, calcium ions are intercalated into the cathode, while the anions in the electrolyte are adsorbed on the surface of the AC counter electrode. On charge, the reverse reaction occurs. The AC-pellet voltage was estimated as $3.08 \mathrm{~V}$ vs. $\mathrm{Ca} / \mathrm{Ca}^{2+}$ by comparing two $\mathrm{CV}$ curves: one using the $\mathrm{Ag} / \mathrm{Ag}^{+}$reference electrode and the other using the $\mathrm{AC}$ reference electrode. Finally, the ferrocene/ferrocenium redox couple voltage was used to calibrate the $\mathrm{Ag} / \mathrm{Ag}^{+}$ electrode voltage.

\subsection{Structural Analysis}

The powder X-ray diffraction (XRD) measurements were performed at $25{ }^{\circ} \mathrm{C}$ using an PANalytical Empyrean X-ray diffractometer in an angular range of $5^{\circ} \leq 2 \theta \leq 150^{\circ}$ (a step of $0.013000^{\circ}$ and the measurement time of $10 \mathrm{~h}$ ), equipped with $\mathrm{Cu} \mathrm{K} \alpha_{1} \mathrm{X}$-ray tube $(\lambda=1.5406 \AA)$, a germanium (111) monochromator, and a PIXcel3D $2 \times 2$ detector.

\section{Results and Discussion}

\subsection{Characterization of the Synthesized Materials}

The phase of the FVO product was confirmed from the Le Bail fitting of the data (Figure 1a), which exhibited no visible impurities. Though the detailed crystal structure has not been determined yet, FVO is considered to have a layered structure including crystal water between layers [32,33] (a proposed structural model in Figure S2). The refined lattice parameters shown in the inset were very close to those for kazakhstanite (JCPDS No. 00-046-1334) [30]. In the Fourier transform infrared (FTIR) transmittance spectrum (Figure $1 \mathrm{~b}$ ), the bond at $1004 \mathrm{~cm}^{-1}$ corresponded to $\mathrm{V}=\mathrm{O}$ stretching, while the absorption bands at 1621, 3191, and $3417 \mathrm{~cm}^{-1}$ indicated the existence of adsorbed water and crystal water in the host structure. The SEM and high-resolution TEM images further confirmed a nanosheet morphology (Figure 1c,d and Figure S3). The TEM image of the nano-flake edge showed layered fringes, indicating a lattice spacing of about $1.0 \mathrm{~nm}$ (Figure $1 \mathrm{~d}$, inset). The thickness of the nano-flake is less than $10 \mathrm{~nm}$. The EDX elemental mappings obtained showed a uniform distribution of Fe, V, and O (Figure 1e). The ICP elemental analysis confirmed that the Fe: $\mathrm{V}$ atomic ratio was 1:3 (Table S1). Combining all the above analyses together with the crystal water content determined from thermogravimetric (TG) analysis (Figure S4), the synthesized material (FVO) was formulated as $\mathrm{FeV}_{3} \mathrm{O}_{9} \cdot 1.2 \mathrm{H}_{2} \mathrm{O}$. Considering that natural kazakhstanite $\left(\mathrm{FeV}_{3} \mathrm{O}_{9} \cdot 2.6 \mathrm{H}_{2} \mathrm{O}\right.$ or $\left.\mathrm{Fe}_{5} \mathrm{~V}_{15} \mathrm{O}_{39}(\mathrm{OH})_{9} \cdot 9 \mathrm{H}_{2} \mathrm{O}\right)$ [30] has more crystal water than we obtained in the lab, the amount of crystal water can be varied depending on the synthetic conditions. The influence of the water content on the properties should be investigated as a future work. 

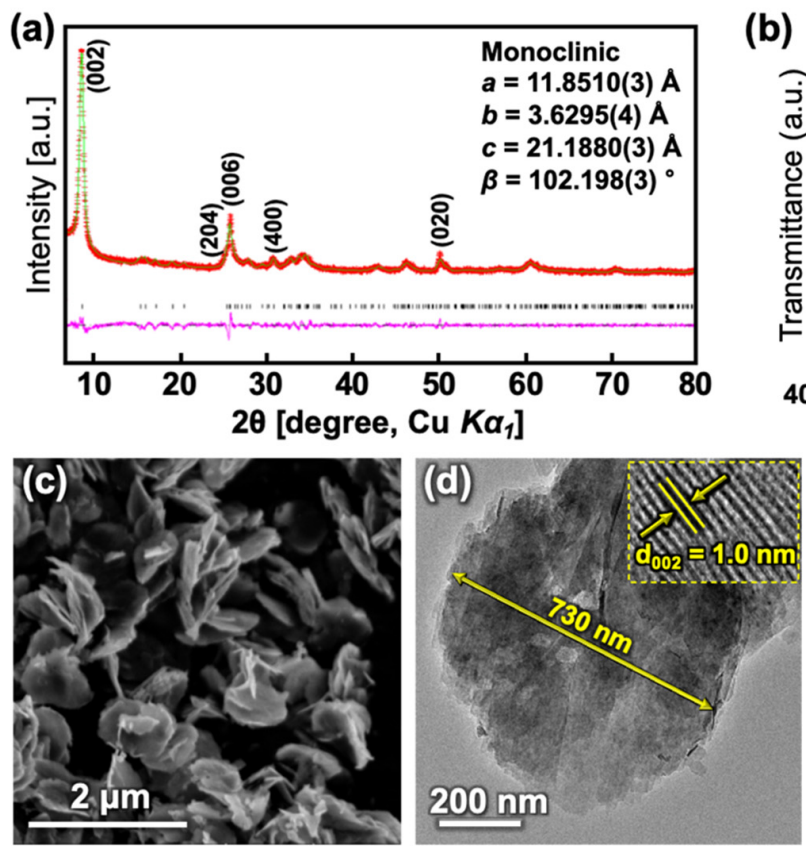

(b)
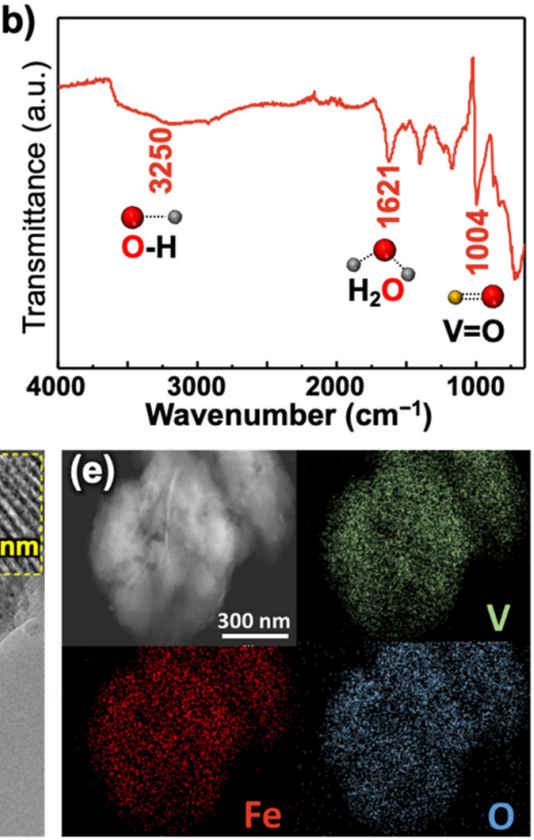

Figure 1. (a) Powder X-ray Le Bail profile, (b) FTIR spectrum, (c) SEM image, (d) magnified TEM image (inset: lattice fringe for $\mathrm{d}_{002}$ ), and (e) EDX elemental mappings for the pristine $\mathrm{FeV}_{3} \mathrm{O}_{9} \cdot 1.2 \mathrm{H}_{2} \mathrm{O}$ sample.

\subsection{Electrochemical Performance of $\mathrm{FeV}_{3} \mathrm{O}_{9} \cdot 1.2 \mathrm{H}_{2} \mathrm{O}$}

The galvanostatic discharge-charge profiles for FVO are presented in Figure 2a. The initial discharge and charge capacities were 334 and $297 \mathrm{mAh} \mathrm{g}^{-1}$, respectively, at $20 \mathrm{~mA} \mathrm{~g}^{-1}$. The second discharge capacity was $303 \mathrm{mAh} \mathrm{g}^{-1}$, which was close to the first charge capacity, indicating good reversibility. The average discharge voltage was about $2.6 \mathrm{~V}$ vs. $\mathrm{Ca} / \mathrm{Ca}^{2+}$, with the potential of the AC electrode being $3.08 \mathrm{~V}$ vs. $\mathrm{Ca} / \mathrm{Ca}^{2+}$ (Figure $2 \mathrm{~d}$, Figures S5 and S6). This reversible capacity ( $\left.303 \mathrm{mAh} \mathrm{g}^{-1}\right)$ is the highest among those reported: Prussian-blue analogues (50-120 $\left.\mathrm{mAh} \mathrm{g}^{-1}\right)$ [10-14], $\mathrm{NaFePO}_{4} \mathrm{~F}\left(\sim 80 \mathrm{mAh} \mathrm{g}^{-1}\right)$ [16], $\mathrm{Ca}_{\mathrm{x}} \mathrm{MoO}_{3}\left(\sim 100 \mathrm{mAh} \mathrm{g}^{-1}\right)$ [19], $\mathrm{Mg}_{0.25} \mathrm{~V}_{2} \mathrm{O}_{5} \cdot \mathrm{H}_{2} \mathrm{O}\left(\sim 110 \mathrm{mAh} \mathrm{g}^{-1}\right)$ [23], $\mathrm{VOPO}_{4} \cdot 2 \mathrm{H}_{2} \mathrm{O}$ $\left(\sim 100 \mathrm{mAh} \mathrm{g}^{-1}\right)$ [24], $\mathrm{NaV}_{2}\left(\mathrm{PO}_{4}\right)_{3}\left(70-80 \mathrm{mAh} \mathrm{g}^{-1}\right)$ [25,26], and $\mathrm{Ca}_{0.13} \mathrm{MoO}_{3} \cdot\left(\mathrm{H}_{2} \mathrm{O}\right)_{0.41}$ $\left(\sim 190 \mathrm{mAh} \mathrm{g}^{-1}\right)$ [27].

The discharge-charge profiles of the second cycle at various current densities are shown in Figure 2b. The discharge capacity decreased significantly with increasing current density. For instance, the discharge capacity at $200 \mathrm{~mA} \mathrm{~g}^{-1}$ was $32 \%$ of that at $20 \mathrm{~mA} \mathrm{~g}^{-1}$ (96 mAh g ${ }^{-1}$ at $200 \mathrm{~mA} \mathrm{~g}^{-1}$ and $303 \mathrm{mAh} \mathrm{g}^{-1}$ at $20 \mathrm{~mA} \mathrm{~g}^{-1}$; see Figure $\mathrm{S} 7$ for rate performance with cycles). It was also noted that the charge capacity contribution of the constant-voltage step also decreased with increasing high current density. These phenomena indicated the low rate-performance of the material due to the slow calcium intercalation kinetics. However, an excellent cycling stability (Figure 2c) was observed-the first discharge capacity $\left(105 \mathrm{mAh} \mathrm{g}^{-1}\right.$ at $\left.200 \mathrm{~mA} \mathrm{~g}^{-1}\right)$ decreased notably till around the first ten cycles but soon stabilized and remained so up to around the 300th cycle. It then gradually decreased up to the 400 th cycle ( $83 \mathrm{mAh} \mathrm{g}^{-1}$ which is $79 \%$ of the first cycle).

The absence of any apparent plateau in the galvanostatic profile suggests that the total capacity might have a significant capacitive contribution. To quantify the contributions from the bulk-intercalation and surface-capacitive reactions [37,38], cyclic voltammograms $(\mathrm{CVs})$ were recorded in the voltage range between -1.5 and $1 \mathrm{~V}$ (vs. AC) at scan rates ranging from 0.05 to $0.5 \mathrm{mV} \mathrm{s}^{-1}$ (Figure 2d). From the current-rate relationship for each reduction and oxidation peak (Figure S8) [37,38], it is evident that the contribution from intercalation was about $81 \%$ at $0.05 \mathrm{mV} \mathrm{s}^{-1}$ (Figure 2e), and the contribution decreased with increasing scan rates $\left(58 \%\right.$ at $\left.0.5 \mathrm{mV} \mathrm{s}^{-1}\right)$. Thus, calcium intercalation was dominant at a lower rate. 
(a)

(c)
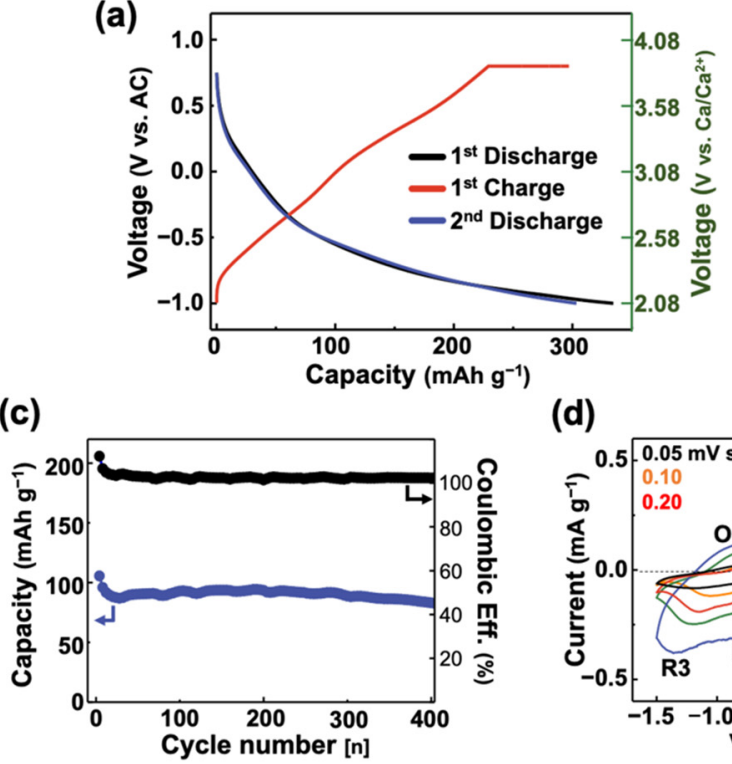

(d)

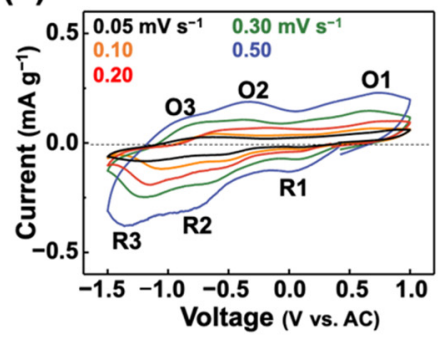

(b)

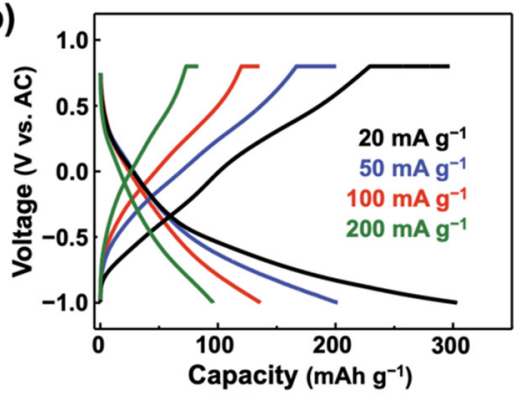

(e)

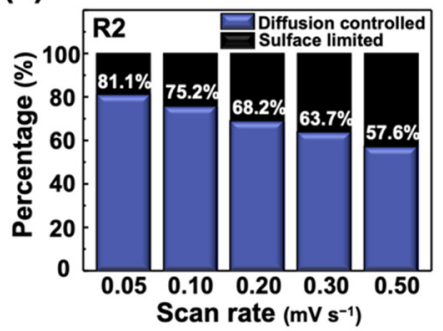

Figure 2. (a) The initial galvanostatic discharge/charge curves at a current density of $20 \mathrm{~mA} \mathrm{~g}^{-1}$, (b) second discharge/charge curves at various currents, (c) cycle performance at $200 \mathrm{~mA} \mathrm{~g}^{-1}$, (d) cyclic voltammograms for the first cycle at various scan rates, (e) ratio of contribution of the diffusion-controlled intercalation and surface-limited capacitive reaction.

According to the ICP elemental analysis (Table S2), the amount of calcium in the discharged FVO electrode was 1.9 Ca per formula unit, which was about $81 \%$ of the value $(2.33 \mathrm{Ca})$ calculated from the discharge capacity $\left(334 \mathrm{mAh} \mathrm{g}^{-1}\right)$. Interestingly, the numerical value of the contribution ( $81 \%$ of the capacity) was coincident with the amount of bulk-intercalated calcium $\left(81 \%\right.$ at $\left.0.05 \mathrm{mV} \mathrm{s}^{-1}\right)$ described above. Most probably, the surface-adsorbed calcium atoms were washed out during the ICP sample preparation, thereby explaining the reduced calcium content. It was also noted that a small portion $(0.2 \mathrm{Ca})$ of the intercalated calcium atoms was trapped in the structure even after being charged (Table S2).

\subsection{Elemental Analysis of $\mathrm{FeV}_{3} \mathrm{O}_{9} \cdot 1.2 \mathrm{H}_{2} \mathrm{O}$}

It is noteworthy that the water content remained almost constant during a cycle, as revealed by the TG analysis (Figure 3a); only the discharged sample showed an increased dehydration temperature, which resulted from the higher structural stability owing to the bonding between the intercalated calcium and the host layers. The retention of water could be an advantageous characteristic of this material when we consider a contrasting case of the potassium intercalation into $\mathrm{VOPO}_{4} \cdot 2 \mathrm{H}_{2} \mathrm{O}$, where the crystal water is removed from the structure upon discharge [39]. FTIR spectra also confirmed the existence of water at all the states of the samples during a cycle (Figure 3b). The SEM images showed that the morphology of FVO was well maintained, without any notable changes (Figure 3c).

Figure 4a shows the powder XRD patterns of the FVO electrodes at different states (pristine and charged/discharged states) during cycles, clearly evidencing the reversibility of the electrochemical calciation during the cycles. The shift of the (001) peak to a higher $2 \theta$ angle on discharge indicated a decreased interlayer space, owing to the attractive interaction between the inserted calcium and the host layer. Upon charging, the peaks re-shifted to a position the same as that of the pristine state, revealing the structural reversibility. The high-resolution TEM image clearly showed a disordered lattice fringe upon discharge, which disappeared on charging (Figure 4b). 
(a)

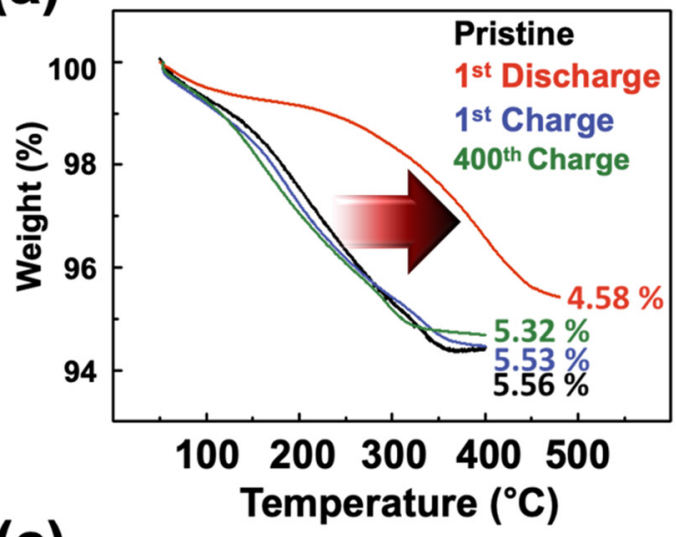

(c)

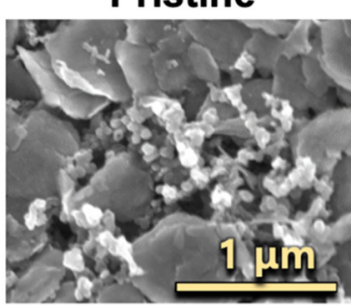

$1^{\text {st }}$ discharge

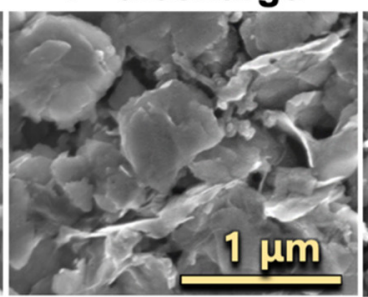

(b)

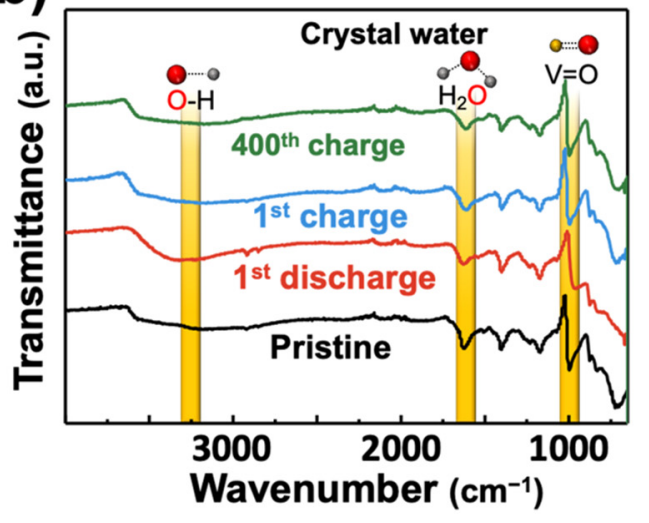

$1^{\text {st }}$ charge

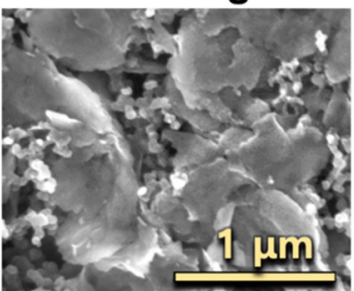

$400^{\text {th }}$ charge

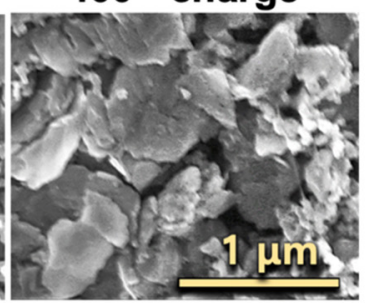

Figure 3. (a) TG analyses under nitrogen atmosphere, (b) FTIR spectra, and (c) SEM images of pristine FVO and FVO after first discharge cycle, first charge cycle, and 400th charge cycle.

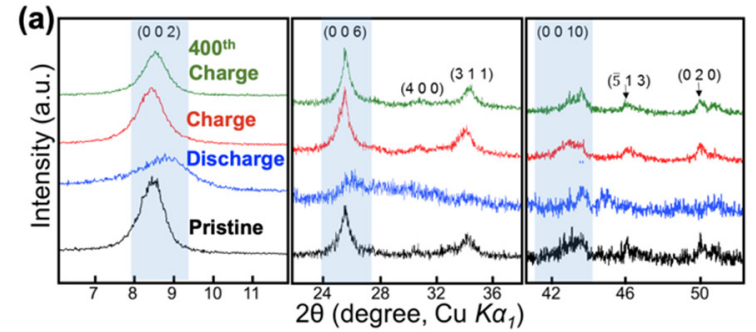

(c)

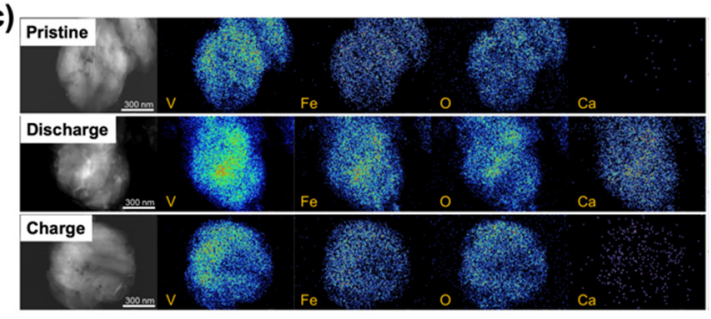

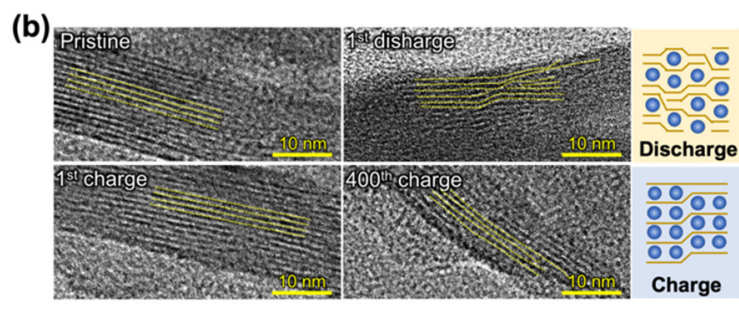

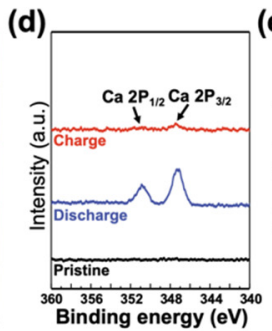

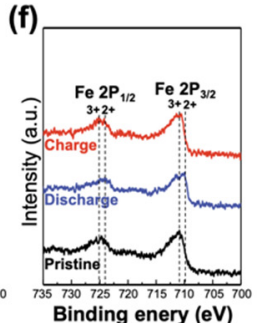

Figure 4. (a) XRD patterns, (b) high-resolution TEM images, (c) TEM-EDX images, (d-f) XPS survey spectra of Ca 2p, V 2p, and Fe $2 p$ spin-orbitals for pristine FVO and FVO after first discharge cycle, first charge cycle, and 400th charge cycle.

This is in good agreement with the broadened peaks and recurring sharp peaks in the XRD patterns. The TEM EDX elemental mappings of pristine, discharged, and charged electrodes are shown in Figure 4c. A uniform distribution of calcium was clearly visible in the discharged FVO particles; this is hardly seen on the charged state, suggesting that calcium ions were the main transfer ions for the redox reaction. Figure $4 \mathrm{~d}-\mathrm{f}$ display the X-ray photoelectron spectroscopy (XPS) survey spectra of Ca 2p, V 2p, and Fe 2p spinorbitals. Calcium ions appeared during discharging and mostly disappeared upon charging, indicating a partial reduction of the vanadium ion, which disappeared on charging. The peak maxima of iron shifted slightly to lower binding energies during discharging and 
re-shifted upon charging. The XPS spectra indicated that both vanadium and iron atoms were the redox centers for the reversible calciation-decalciation reaction.

\section{Conclusions}

In summary, $\mathrm{FeV}_{3} \mathrm{O}_{9} \cdot 1 \cdot 2 \mathrm{H}_{2} \mathrm{O}$ has been demonstrated as a new potential high-performance cathode host material with high capacity and excellent cyclability for nonaqueous calciumion batteries at room temperature. The material was synthesized via a facile co-precipitation method and showed high electrochemical performance as an calcium-ion battery cathode material. It exhibited a reversible discharge capacity of $303 \mathrm{mAh} \mathrm{g}^{-1}$ at $20 \mathrm{~mA} \mathrm{~g}^{-1}$ with a good cyclability and an average discharge voltage of $\sim 2.6 \mathrm{~V}\left(\mathrm{vs} . \mathrm{Ca} / \mathrm{Ca}^{2+}\right)$. It is the highest reversible capacity among those reported for calcium-ion battery cathode materials. Bulk intercalation contributed dominantly to the total capacity at lower scan rates; however, it became comparable to surface adsorption at higher rates. X-ray diffraction, elemental, electrochemical, and XPS analyses unambiguously evidenced the reversible calcium insertion into the host material. As a further study, the atomic-scale crystal structures of the synthesized and cycled phases should be determined to deeply understand the calcium storage mechanism of this material.

In spite of the several potential advantages of using calcium, the development of a high-performance calcium-ion battery cathode material was known to be practically challenging to date. Therefore, our findings will provide a stimulus to the on-going research and will open up unexplored opportunities for discovering superior cathode materials for calcium-ion batteries.

Supplementary Materials: The following are available online at https:/ /www.mdpi.com/article/10 $.3390 /$ batteries7030054/s1, Figure S1: Scheme of the homemade cell used for electrochemical characterizations, Figure S2: A proposed crystal structural model for $\mathrm{FeV}_{3} \mathrm{O}_{9} \cdot 1.2 \mathrm{H}_{2} \mathrm{O}$, Figure S3: TEM images of the synthesized $\mathrm{FeV}_{3} \mathrm{O}_{9} \cdot 1.2 \mathrm{H}_{2} \mathrm{O}$ particles, Figure S4: Thermogravimetric analysis for pristine $\mathrm{FeV}_{3} \mathrm{O}_{9} \cdot 1.2 \mathrm{H}_{2} \mathrm{O}$ sample under nitrogen flowing atmosphere, Figure S5: $\mathrm{CV}$ of $\mathrm{FeV}_{3} \mathrm{O}_{9} \cdot 1.2 \mathrm{H}_{2} \mathrm{O}$ electrode at $0.2 \mathrm{mV} \mathrm{s}^{-1}$ in $0.5 \mathrm{M} \mathrm{Ca}\left(\mathrm{ClO}_{4}\right)_{2}$ in $\mathrm{AN}$ with $\mathrm{Ag} / \mathrm{Ag}^{+}$reference electrode in a threeelectrode system, Figure S6: Ferrocene/ferrocenium redox couple CV test to estimate the AC voltage vs. $\mathrm{Ca} / \mathrm{Ca}^{2+}$, Figure S7: Cycle performance with various C-rates, Figure S8: (a) $\mathrm{Log}-\log$ plot of cathodic/anodic peak current dependence on the scan rate. (b) Plot of peak current $\left(\mathrm{i} / \mathrm{v}^{1 / 2}\right)$ dependence on the square root of scan rate $\left(\mathrm{mV}^{1 / 2} \mathrm{~s}^{-1 / 2}\right)$. Table S1: Elemental ratios estimated from ICP analysis for $\mathrm{FeV}_{3} \mathrm{O}_{9} \cdot 1.2 \mathrm{H}_{2} \mathrm{O}$ sample, Table S2: Elemental ratios estimated from ICP analysis for the pristine $\mathrm{FeV}_{3} \mathrm{O}_{9} \cdot 1.2 \mathrm{H}_{2} \mathrm{O}$, first discharged, and first charged electrodes.

Author Contributions: Conceptualization: M.S.C. and S.-T.H.; methodology: M.S.C., D.S. and H.J.K.; supervision: S.-T.H.; writing-original draft preparation: M.S.C.; writing review and editing: S.-T.H. All authors have read and agreed to the published version of the manuscript.

Funding: This work was supported by the Samsung Research Funding \& Incubation Center of Samsung Electronics under Project Number SRFC-MA1601-04. This work also was supported by the Creative Materials Discovery Program through the National Research Foundation of Korea funded by the Ministry of Science, ICT and Future Planning (Grant 2015M3D1A1069707).

Conflicts of Interest: The authors declare no conflict of interest.

\section{References}

1. Choi, J.W.; Aurbach, D. Promise and reality of post-lithium-ion batteries with high energy densities. Nat. Rev. Mater. 2016, 1, 1603. [CrossRef]

2. Ponrouch, A.; Bitenc, J.; Dominko, R.; Lindahl, N.; Johansson, P.; Palacin, M.R. Multivalent rechargeable batteries. Energy Storage Mater. 2019, 20, 253-262. [CrossRef]

3. Arroyo-de Dompablo, M.E.P.; Ponrouch, A.; Johansson, P.; Palacín, M. Rosa Achievements, Challenges, and Prospects of Calcium Batteries. Chem. Rev. 2020, 120, 6331-6357. [CrossRef]

4. Gummow, R.J.; Vamvounis, G.; Kannan, M.B.; He, Y. Calcium-ion batteries: Current state-of-the-art and future perspectives. Adv. Mater. 2018, 30, 1801702. [CrossRef] [PubMed] 
5. Maroni, F.; Dongmo, S.; Gauckler, C.; Marinaro, M.; Wohlfahrt-Mehrens, M. Through the Maze of Multivalent-Ion Batteries: A Critical Review on the Status of the Research on Cathode Materials for $\mathrm{Mg}^{2+}$ and $\mathrm{Ca}^{2+}$ Ions Insertion. Batter. Supercaps 2021. [CrossRef]

6. Ponrouch, A.; Frontera, C.; Bardé, F.; Palacín, M.R. Towards a calcium-based rechargeable battery. Nat. Mater. 2016, 15, 169-172. [CrossRef]

7. Wang, D.; Gao, X.; Chen, Y.; Jin, L.; Kuss, C.; Bruce, P.G. Plating and stripping calcium in an organic electrolyte. Nat. Mater. 2018, 17, 16. [CrossRef]

8. Wang, M.; Jiang, C.; Zhang, S.; Song, X.; Tang, Y.; Cheng, H.-M. Reversible calcium alloying enables a practical room-temperature rechargeable calcium-ion battery with a high discharge voltage. Nat. Chem. 2018, 10, 667. [CrossRef]

9. Rogosic, J. Towards the Development of Calcium Ion Batteries. Ph.D. Thesis, Massachusetts Institute of Technology, Cambridge, MA, USA, 2014.

10. Kuperman, N.; Padigi, P.; Goncher, G.; Evans, D.; Thiebes, J.; Solanki, R. High performance Prussian Blue cathode for nonaqueous Ca-ion intercalation battery. J. Power Sources 2017, 342, 414-418. [CrossRef]

11. Tojo, T.; Sugiura, Y.; Inada, R.; Sakurai, Y. Reversible calcium ion batteries using a dehydrated prussian blue analogue cathode. Electrochim. Acta 2016, 207, 22-27. [CrossRef]

12. Lipson, A.L.; Han, S.-D.; Kim, S.; Pan, B.; Sa, N.; Liao, C.; Fister, T.T.; Burrell, A.K.; Vaughey, J.T.; Ingram, B.J. Nickel hexacyanoferrate, a versatile intercalation host for divalent ions from nonaqueous electrolytes. J. Power Sources 2016, 325, 646-652. [CrossRef]

13. Padigi, P.; Goncher, G.; Evans, D.; Solanki, R. Potassium barium hexacyanoferrate-A potential cathode material for rechargeable calcium ion batteries. J. Power Sources 2015, 273, 460-464. [CrossRef]

14. Lipson, A.L.; Pan, B.F.; Lapidus, S.H.; Liao, C.; Vaughey, J.T.; Ingram, B.J. Rechargeable Ca-Ion Batteries: A New Energy Storage System. Chem. Mater. 2015, 27, 8442-8447. [CrossRef]

15. Cabello, M.; Nacimiento, F.; González, J.R.; Ortiz, G.; Alcántara, R.; Lavela, P.; Pérez-Vicente, C.; Tirado, J.L. Advancing towards a veritable calcium-ion battery: $\mathrm{CaCo}_{2} \mathrm{O}_{4}$ positive electrode material. Electrochem. Commun. 2016, 67, 59-64. [CrossRef]

16. Lipson, A.L.; Kim, S.; Pan, B.; Liao, C.; Fister, T.T.; Ingram, B.J. Calcium intercalation into layered fluorinated sodium iron phosphate. J. Power Sources 2017, 369, 133-137. [CrossRef]

17. Vo, T.N.; Kim, H.; Hur, J.; Choi, W.; Kim, I.T. Surfactant-assisted ammonium vanadium oxide as superior cathode for calcium-ion batteries. J. Mater. Chem. A 2018, 6, 22645-22654. [CrossRef]

18. Tojo, T.; Tawa, H.; Oshida, N.; Inada, R.; Sakurai, Y. Electrochemical characterization of a layered $\alpha-\mathrm{MoO}_{3}$ as a new cathode material for calcium ion batteries. J. Electroanal. Chem. 2018, 825, 51-56. [CrossRef]

19. Cabello, M.; Nacimiento, F.; Alcantara, R.; Lavela, P.; Vicente, C.P.; Tirado, J.L. Applicability of Molybdite as an Electrode Material in Calcium Batteries: A Structural Study of Layer-type $\mathrm{Ca}_{x} \mathrm{MoO}_{3}$. Chem. Mater. 2018, 30, 5853-5861. [CrossRef]

20. Tchitchekova, D.S.; Ponrouch, A.; Verrelli, R.; Broux, T.; Frontera, C.; Sorrentino, A.; Barde, F.; Biskup, N.; Arroyo-de Dompablo, M.E.; Palacín, M.R. Electrochemical Intercalation of Calcium and Magnesium in $\mathrm{TiS}_{2}$ : Fundamental Studies Related to Multivalent Battery Applications. Chem. Mater. 2018, 30, 847-856. [CrossRef]

21. Murata, Y.; Takada, S.; Obata, T.; Tojo, T.; Inada, R.; Sakurai, Y. Effect of water in electrolyte on the Ca ${ }^{2+}$ insertion/extraction properties of $\mathrm{V}_{2} \mathrm{O}_{5}$. Electrochim. Acta 2019, 294, 210-216. [CrossRef]

22. Pathreeker, S.; Reed, S.; Chando, P.; Hosein, I.D. A study of calcium ion intercalation in perovskite calcium manganese oxide. J. Electroanal. Chem. 2020, 874, 114453. [CrossRef]

23. Xu, X.; Duan, M.; Yue, Y.; Li, Q.; Zhang, X.; Wu, L.; Wu, P.; Song, B.; Mai, L. Bilayered $\mathrm{Mg}_{0.25} \mathrm{~V}_{2} \mathrm{O}_{5} \cdot \mathrm{H}_{2} \mathrm{O}$ as a Stable Cathode for Rechargeable Ca-Ion Batteries. ACS Energy Lett. 2019, 4, 1328-1335. [CrossRef]

24. Wang, J.; Tan, S.; Xiong, F.; Yu, R.; Wu, P.; Cui, L.; An, Q. VOPO $\mathrm{VO}_{4} \cdot 2 \mathrm{H}_{2} \mathrm{O}$ as a new cathode material for rechargeable Ca-ion batteries. Chem. Commun. 2020, 56, 3805-3808. [CrossRef] [PubMed]

25. Jeon, B.; Heo, J.W.; Hyoung, J.; Kwak, H.H.; Lee, D.M.; Hong, S.-T. Reversible Calcium-Ion Insertion in NASICON-Type $\mathrm{NaV}_{2}\left(\mathrm{PO}_{4}\right)_{3}$. Chem. Mater. 2020, 32, 8772-8780. [CrossRef]

26. Kim, S.; Yin, L.; Lee, M.H.; Parajuli, P.; Blanc, L.; Fister, T.T.; Park, H.; Kwon, B.J.; Ingram, B.J.; Zapol, P.; et al. High-Voltage Phosphate Cathodes for Rechargeable Ca-Ion Batteries. ACS Energy Lett. 2020, 5, 3203-3211. [CrossRef]

27. Chae, M.S.; Kwak, H.H.; Hong, S.-T. Calcium Molybdenum Bronze as a Stable High-Capacity Cathode Material for Calcium-Ion Batteries. ACS Appl. Energy Mater. 2020, 3, 5107-5112. [CrossRef]

28. Hess, F.L.; Henderson, E.P. Fervanite, a hydrous ferric vanadate. Am. Mineral. 1931, 16, $273-277$.

29. Weeks, A.D.; Thompson, M.E.; Sherwood, A.M. Navajoite, a new vanadium oxide from Arizona. Am. Mineral. 1955, 40, $207-212$. [CrossRef] [PubMed]

30. Ankinovitch, E.A.; Bekenova, G.K.; Podlipaeva, N.I. Fe ${ }^{3+}{ }_{5} \mathrm{~V}^{4+}{ }_{3} \mathrm{~V}^{5+}{ }_{12} \mathrm{O}_{39}(\mathrm{OH})_{9} \cdot 8.55 \mathrm{H}_{2} \mathrm{O}$, a new hydrous ferrovanadian mineral from carbonaceous-siliceous formation, the Nw Karatau (South Kazakhstan). Proc. Russ. Mineral. Soc. 1989, 118, 95-100.

31. Poizot, P.; Laruelle, S.; Touboul, M.; Tarascon, J.-M. Wet-chemical synthesis of various iron (III) vanadates (V) by co-precipitation route. Comptes Rendus Chim. 2003, 6, 125-134. [CrossRef]

32. Wei, Q.; Wang, Q.; Li, Q.; An, Q.; Zhao, Y.; Peng, Z.; Jiang, Y.; Tan, S.; Yan, M.; Mai, L. Pseudocapacitive layered iron vanadate nanosheets cathode for ultrahigh-rate lithium ion storage. Nano Energy 2018, 47, 294-300. [CrossRef] 
33. Peng, Z.; Wei, Q.; Tan, S.; He, P.; Luo, W.; An, Q.; Mai, L. Novel layered iron vanadate cathode for high-capacity aqueous rechargeable zinc batteries. Chem. Commun. 2018, 54, 4041-4044. [CrossRef] [PubMed]

34. Lee, D.; Bu, H.; Kim, D.; Hyoung, J.; Hong, S.-T. Crystal structure of calcium perchlorate anhydrate, $\mathrm{Ca}\left(\mathrm{ClO}_{4}\right)_{2}$, from laboratory powder X-ray diffraction data. Acta Cryst. 2018, E74, 514-517. [CrossRef]

35. Gershinsky, G.; Yoo, H.D.; Gofer, Y.; Aurbach, D. Electrochemical and spectroscopic analysis of $\mathrm{Mg}^{2+}$ intercalation into thin film electrodes of layered oxides: $\mathrm{V}_{2} \mathrm{O}_{5}$ and $\mathrm{MoO}_{3}$. Langmuir 2013, 29, 10964-10972. [CrossRef]

36. Ruch, P.W.; Cericola, D.; Hahn, M.; Kötz, R.; Wokaun, A. On the use of activated carbon as a quasi-reference electrode in non-aqueous electrolyte solutions. J. Electroanal. Chem. 2009, 636, 128-131. [CrossRef]

37. Wang, J.; Polleux, J.; Lim, J.; Dunn, B. Pseudocapacitive contributions to electrochemical energy storage in $\mathrm{TiO}_{2}($ anatase) nanoparticles. J. Phys. Chem. C 2007, 111, 14925-14931. [CrossRef]

38. Yin, H.; Song, C.; Wang, Y.; Li, S.; Zeng, M.; Zhang, Z.; Zhu, Z.; Yu, K. Influence of morphologies and pseudocapacitive contributions for charge storage in $\mathrm{V}_{2} \mathrm{O}_{5}$ micro/nano-structures. Electrochim. Acta 2013, 111, 762-770. [CrossRef]

39. Hyoung, J.; Heo, J.W.; Chae, M.S.; Hong, S.T. Electrochemical Exchange Reaction Mechanism and the Role of Additive Water to Stabilize the Structure of $\mathrm{VOPO}_{4} \cdot 2 \mathrm{H}_{2} \mathrm{O}$ as a Cathode Material for Potassium-Ion Batteries. ChemSusChem 2019, 12, $1069-1075$. [CrossRef] [PubMed] 